\title{
HCI Brazilian Community - After 10 Years
}

\author{
Raquel Oliveira Prates ${ }^{1,2}$ \\ ${ }^{1}$ Departamento de Ciência da Computação - UFMG, \\ Av. Antônio Carlos, 6627, Prédio do ICEx, sala 4010, Belo Horizonte - MG \\ rprates@dcc.ufmg.br \\ ${ }^{2}$ Chair of the Special Interest Group in Human-Computer Interacton (CEIHC) \\ Brazilian Computer Society (SBC)
}

\begin{abstract}
The Brazilian HCI community first started organizing itself in 1997 and after 10 years has grown and consolidated itself nationally and internationally.
\end{abstract}

Keywords: Brazil, HCI community, Brazilian Computer Society, SBC, CEIHC, Brazil-CHI, BR-CHI, SIGCHI, IFIP.

Research in HCI in Brazil started in the end of 80's and beginning the 90's. At that time there were a few researchers who were interested in the discipline. By the end of 90's, although some of these researchers had been doing work on HCI for a decade, there was no HCI community in Brazil. In 1997, after some Ph.D. students participated in CHI 2007 they thought it would be interesting to find out who was working with HCI in Brazil. With the support of Professor Clarisse de Souza they started the efforts in that direction. The first step was to create a website containing the information on people (mainly professors and grad students) working in the field and their work.

In that same year at CHI, Richard Anderson who was SIGCHI Chair for Local Chapters at the time encouraged the group to create a Brazilian Local Chapter. The Brazilian Local Chapter (or BR-CHI) was created as a prospective chapter [1]. BR-CHI allowed us to exchange experiences with different HCI communities worldwide that were facing or had faced similar challenges as the ones ahead of us trying to consolidate the Brazilian HCI community. Also it played an important role as the first formal HCI organization in which people working or interested in the field in Brazil could get in touch with or become a member of.

The following year, 1998, the first HCI event (IHC) was organized in Brazil as a 3 day workshop organized within the Brazilian Symposium on Software Engineering. The workshop was successful and became an annual event for the Brazilian HCI community. In its $5^{\text {th }}$ edition in 2002 the event became a Symposium. That same year was created the Special Interest Group in Human-Computer Interaction (CEIHC) in the Brazilian Computer Society (SBC) [2]. The HCI community was growing and consolidating itself within Brazil as well as internationally. In 1999, the Brazilian Computer Society designated the first representative for the Brazilian HCI community to participate in IFIP-TC13. In 2000, Br-CHI became a SIGCHI chartered chapter and in 2001, CHI organized a Development Consortium on HCI in Latin America. During this consortium the idea of having a Latin-American HCI conference was discussed. 
In IHC 2002, the idea became a plan, and IHC started to alternate every other year with the Latin-American Conference in HCI (CLIHC). The first edition of CLIHC was held in Rio de Janeiro in 2003, the $2^{\text {nd }}$ in Mexico in 2005, and its $3^{\text {rd }}$ edition will be organized as part of INTERACT 2007. In 2006, for the first time IHC proceedings have been published in ACM/DL. Finally, in 2007, the Brazilian HCI community is honored to be hosting INTERACT, in its first edition south of the equator.

The Brazilian HCI community has come a long way from having a directory of people interested in HCI in 1997 to hosting INTERACT 2007. In these 10 years some of the relevant achievements the Brazilian HCI community has accomplished are:

- A consolidated event (IHC) that brings together the Brazilian HCI community;

- Participation of members of the Brazilian HCI community in organizing and program committees of relevant international HCI events;

- Representatives in relevant scientific societies in Brazil (SBC) and internationally (SIGCHI/ACM, IFIP);

- Relevant publications of results of HCI research in Brazil in a number of international events and journals;

- Participation of members of the Brazilian HCI community in editorial boards of relevant HCI journals;

- Publication of a book about an HCI theory developed in Brazil aimed at the international HCI community by MIT Press [3];

- Publication of educational material on HCI in Portuguese as books or chapters of Brazilian computing books, and translation of a well known and recommended book to Portuguese [4];

- Recommendation of HCI as a mandatory course to Computer Science and Information System curricula by SBC;

- Initial recommendation and discussion on a program for an HCI course at undergrad level, and possibilities for grad level courses;

- An increasing number of HCI professors and researchers in Universities, as well as professionals in industry;

We hope that experience of the Brazilian HCI community can be used by other HCI communities to get started, consolidated or have an active role scientifically. One important ingredient that has been essential to our community to succeed has been the dedication and willingness to participate and make it happen of all its members.

\section{References}

1. BrCHI - SIGCHI/ACM Brazil CHI Local Chapter, available at: http://ead.unifor.br/brchi/

2. CEIHC - Comissão Especial de IHC da SBC (HCI Special Interest Group in the Brazilian Computer Society. available at: http:// www.sbc.org.br/ihc

3. de Souza, C.S.: The Semiotic Engineering of Human-Computer Interaction. The MIT Press, Cambridge (2005)

4. Preece, J., Rogers, Y., Sharp, H.: Design de Interação: Além da Interação HomemComputador. Bookman, Porto Alegre (2005) 